\title{
Impact of citrate pretreatment on ventricular arrhythmia and myocardial capase- 3 expression in ischemia/reperfusion injury
}

\author{
Q. Lu ${ }^{1,2}$, Z.G. Li ${ }^{1,2}$, N. Zhou ${ }^{3}$, Z.G. Gong ${ }^{1,2}$, J.Q. Jiang ${ }^{1,2}$, Z.N. Chen ${ }^{1,2}$, \\ Q.J. Jiang ${ }^{1,2}$, Y. Peng ${ }^{1,2}$ and S.F. Ding ${ }^{1,2}$ \\ ${ }^{1}$ Southern Medical University, Guangzhou, Guangdong, China \\ ${ }^{2}$ Department of Cardiology, Wuhan General Hospital of PLA, Wuhan, Hubei, \\ China \\ ${ }^{3}$ Department of Cardiology, Tongji Hospital, \\ Tongji Medical College of Huazhong University of Science and Technology, \\ Wuhan, Hubei, China \\ Corresponding author: S.F. Ding \\ E-mail: dingshifangl@sina.com
}

Genet. Mol. Res. 15 (4): gmr15048848

Received June 2, 2016

Accepted August 10, 2016

Published October 17, 2016

DOI http://dx.doi.org/10.4238/gmr15048848

Copyright (C) 2016 The Authors. This is an open-access article distributed under the terms of the Creative Commons Attribution ShareAlike (CC BY-SA) 4.0 License.

\begin{abstract}
Ischemia/reperfusion (I/R) injury often triggers ventricular arrhythmia. Citrate binds calcium ions, forming a soluble calcium citrate complex that may reduce $I / R$ injury by affecting calcium ion concentration. We tested the effects of citrate pretreatment on ventricular heart rate and related factors in a rat I/R model. Fifty male Sprague Dawley rats weighing 350-400 g were randomly divided into equally sized control (A), model (B), and 0.1 M (C), $0.05 \mathrm{M}$ (D), and $0.025 \mathrm{M}(\mathrm{E})$ citrate groups. An $\mathrm{I} / \mathrm{R}$ model was established by ligating the left anterior descending coronary artery. Serum calcium ion concentration was measured before and after citrate treatment.
\end{abstract}


Triphenyltetrazolium chloride staining and spectrophotometry were used to determine infarction area and caspase-3 protein levels in myocardial tissue, respectively. Polymerase chain reaction was performed to test myocardial calmodulin (CAM) expression. The frequency of ventricular arrhythmia in group B was significantly higher than in the sham surgery group $(\mathrm{P}<0.05)$. Citrate pretreatment resulted in lower and higher frequencies than those observed in the model and control groups, respectively, in a dose-independent manner. The most obvious reduction in ventricular arrhythmia was seen in Group D. Serum calcium ion concentration decreased markedly after citrate treatment $(\mathrm{P}<0.05)$, with a specific pattern emerging over time. Infarction area and caspase- 3 and CAM levels were significantly lower in the citrate groups compared with the model group $(\mathrm{P}<0.05)$. Citrate can reduce myocardial cell apoptosis, alleviating ventricular arrhythmia and protecting the myocardium by reducing serum calcium ion concentration and downregulating caspase-3 and CAM expression.

Key words: Citrate; Ventricular arrhythmia; Caspase-3

\section{INTRODUCTION}

Acute myocardial infarction is an important cause of sudden cardiac death. Early acute myocardial ischemia and injury lead to unstable cardiac electrical activity and ventricular repolarization, triggering malignant arrhythmia and sudden death (Fanton et al., 2015; Horvat and Vincelj, 2015). Myocardial ischemia/reperfusion (I/R) may aggravate cardiac dysfunction and myocardial cell injury. Thus, it is important to clarify the mechanisms by which $\mathrm{I} / \mathrm{R}$ injury can be prevented (Huang et al., 2015; Shekarforoush et al., 2016). Intracellular calcium overload has a leading role in myocardial I/R injury (Gonca and Kurt, 2015; Patil et al., 2015). During I/R, intracellular calcium stores are thought to release $\mathrm{Ca}^{2+}$ into the cell, leading to dysregulation of its influx, exacerbating $\mathrm{Ca}^{2+}$ overload. Mitochondrial adenosine triphosphate (ATP) production decreases, calcium pump function is restricted, and $\mathrm{Na}^{+} / \mathrm{Ca}^{2+}$ exchangers as ATP-independent transporters induce elevation of intracellular $\mathrm{Na}^{+}$and acidosis during myocardial ischemia hypoxia. $\mathrm{pH}$ and ATP levels then recover during myocardial reperfusion. The resulting $\mathrm{pH}$ gradient across the cell membrane activates $\mathrm{Na}^{+} / \mathrm{H}^{+}$and $\mathrm{Na}^{+} / \mathrm{Ca}^{2+}$ exchange and $\mathrm{Ca}^{2+}$ influx, leading to intracellular calcium overload. This can cause lack of myocardial depolarization following an action potential, triggering ventricular arrhythmia (Miskolczi et al., 2015; Wu et al., 2015). Mitochondria regulate intracellular calcium levels through a variety of mechanisms. Oxygen free radical production increases during myocardial ischemia hypoxia, resulting in mitochondrial dysfunction and diminished ATP generation. Energy-dependent calcium pumps in membranes of the endoplasmic reticulum, sarcoplasmic reticulum, and cell are therefore blocked. Accordingly, excessive intracellular $\mathrm{Ca}^{2+}$ cannot be sequestrated or excluded, finally causing $\mathrm{Ca}^{2+}$ overload (Barrabés et al., 2015; Szepesi et al., 2015). Calcium can promote the formation and release of fibrin, thrombin, and blood coagulation factor III by activating platelets in the coagulation process. As an anticoagulant, citrate forms calcium citrate with calcium ions, reducing their concentration in the blood, and inhibiting coagulation. To date, the role of citrate in myocardial I/R has received little attention. This study employed

Genetics and Molecular Research 15 (4): gmr15048848 
left anterior descending coronary artery ligation to establish a rat model of coronary I/R. The effect of citrate pretreatment on ventricular arrhythmia, serum calcium concentration, and caspase- 3 protein and calmodulin (CAM) expression in the myocardium was measured, providing a basis for the prevention of myocardial I/R injury in clinical practice.

\section{MATERIAL AND METHODS}

\section{Experimental animals and groups}

Healthy male 10-week-old Sprague Dawley rats weighing 350-400 g were provided by the Animal Experiment Center of Tongji Medical College of Huazhong University of Science and Technology (license SYXK-2013-0025). The rats were kept in a specific-pathogen-free laboratory in accordance with experimental animal standards, and were randomly divided into control (A), model (B), and citrate acid pretreatment (C, D, and E) groups, with 10 individuals in each group. Those in groups $\mathrm{C}, \mathrm{D}$, and $\mathrm{E}$ received intravenous injections in the tail of 0.1 , 0.05 , and $0.025 \mathrm{M}$ citrate, respectively, $10 \mathrm{~min}$ before reperfusion. The volume injected was $1 \mathrm{~mL}$ (according to the clinical dosage equivalent conversion). The rats then received $50 \mu \mathrm{L}$ physiological saline intubation, with an equal volume of saline given to those in groups A and B.

Rats were used for all experiments, and all procedures were approved by the Animal Ethics Committee of Wuhan General Hospital of Guangzhou Military.

\section{Drugs and reagents}

Citrate acid was purchased from ZsBio (Beijing, China). Triphenyltetrazolium chloride (TTC) and urethane were obtained from Sigma (St. Louis, MO, USA). TTC (0.1 g) was dissolved in $5 \mathrm{~mL}$ phosphate-buffered saline (PBS) before use. A caspase-3 kit was supplied by Biobox (Nanjing, China), and a bicinchoninic acid (BCA) protein assay kit was purchased from Pierce (Waltham, MA, USA). The QIAamp DNeasy Blood \& Tissue Kit was manufactured by QIAGEN (Düsseldorf, Germany). Taq polymerase chain reaction (PCR) reagents were provided by Thermo Scientific (Waltham, MA, USA).

\section{Rat model}

The rat $\mathrm{I} / \mathrm{R}$ model was established according to a previously published method (Liu et al., 2014). Rats were administered 5\% urethane for abdominal cavity anesthesia, and a 24-guage needle was retained in the caudal vein. The animals were fixed and connected to an electrocardiogram (ECG; lead II configuration) and animal ventilator to control breathing rate (tidal volume, $8 \mathrm{~mL} / \mathrm{kg}$; frequency, 70 breaths $/ \mathrm{min}$; inspiration:expiration ratio, 1:2). The left common carotid artery was separated to connect the electrophysiological signal recorder. The root of the left anterior descending coronary artery was ligated, whereas control rats underwent threading but not ligation. After $30 \mathrm{~min}$ of ischemia, reperfusion was carried out for $2 \mathrm{~h}$, and ECG changes were recorded. Ischemia was deemed to have occurred if, after the left anterior descending coronary artery had been ligated for $5 \mathrm{~min}$, lead II showed ST elevation or increased QRS complex amplitude and broadening fusion with the $\mathrm{T}$ wave, arterial blood pressure lowered by $>20 \mathrm{mmHg}$, and cyanosis appeared in the vascular ligation area. Reperfusion was defined as disappearance of the cyanotic area, decrease of the elevated ST segment by $>50 \%$

Genetics and Molecular Research 15 (4): gmr15048848 
30 min after reperfusion, elimination of the severe atrioventricular block before reperfusion, and mean arterial pressure before ligation $<60 \mathrm{mmHg}$. Rats were euthanized and the heart tissue was collected for determination of serum calcium ion concentration before and after pretreatment, infarction area, capase-3 protein expression, and myocardial CAM levels.

\section{TTC staining for infarction area determination}

After being washed in PBS, the left ventricle was frozen at $-80^{\circ} \mathrm{C}$ and cut into $5-\mathrm{mm}$ slices. Sections were incubated in $1 \%$ TTC solution, $\mathrm{pH} 8.5$, at $37^{\circ} \mathrm{C}$ for $0.5 \mathrm{~h}$. The infarction area showed no staining, and normal tissue appeared reddish brown. The Image-Pro Plus 6.0 software (Media Cybernetics, Inc., Rockville, MD, USA) was used to calculate infarct size (IS) relative to the left ventricle (IS/LV) and area at risk (IS/AAR), and AAR in relation to the LV (AAR/LV).

\section{Spectrophotometric detection of myocardial capase-3 expression}

Heart tissue in the infarction area was isolated to detect protein levels with a BCA assay kit, and caspase- 3 protein expression in myocardial tissue was estimated by the colorimetric method, following the manufacturer protocol.

\section{PCR}

DNA was extracted from tissues using a QIAamp DNeasy Blood \& Tissue Kit, and its concentration determined with a NanoDrop 2000 spectrophotometer (Thermo Scientific). PCR was applied to test target gene expression. Reaction conditions were as follows: $95^{\circ} \mathrm{C}$ for $5 \mathrm{~min}$, followed by 32 cycles of $94^{\circ} \mathrm{C}$ for $30 \mathrm{~s}, 55^{\circ} \mathrm{C}$ for $45 \mathrm{~s}$, and $72^{\circ} \mathrm{C}$ for $60 \mathrm{~s}$, following the manufacturer protocol. $\beta$-actin was used as an internal reference. PCR was performed on complementary DNA templates. The following primers were used: CAM forward, 5'-GCT GCC TCT TCA AAA TCG CC-3', and reverse, 5'-CTC TGC ACT GTG TAC CTC GG-3'; $\beta$-actin forward, 5'-GAG AGG GAA ATC GTG CGT GAC-3', and reverse, 5'-CAT CTG CTG GAA GGT GGA CA-3'. Products were visualized by electrophoresis on a 1\% agarose gel using a Gel Doc EZ gel documentation system (Bio-Rad, Hercules, CA, USA).

\section{Statistical analysis}

All statistical analyses were performed with the SPSS 19.0 software (IBM, Armonk, NY, USA). Measurement data conforming to a normal distribution are reported as means \pm standard deviations. Chi-square, one-way analysis of variance, and least significant difference tests were applied for comparison of means. $\mathrm{P}<0.05$ was considered statistically significant.

\section{RESULTS}

\section{Effect of citrate pretreatment on ventricular premature beat frequency}

In comparison with control animals, model rats exhibited a significantly higher frequency of ventricular premature beats $(\mathrm{P}<0.05)$. By contrast, in the citrate groups, these

Genetics and Molecular Research 15 (4): gmr15048848 
events were less frequent compared with the model group, but more common than in the control group $(\mathrm{P}<0.05)$. Group $\mathrm{D}$ significantly differed from groups $\mathrm{C}$ and $\mathrm{E}$ in this respect $(\mathrm{P}<0.05)$, indicating that citrate may decrease the frequency of ventricular premature beats in a doseindependent manner, with a concentration of $0.05 \mathrm{M}$ having the strongest effect (Figure 1).

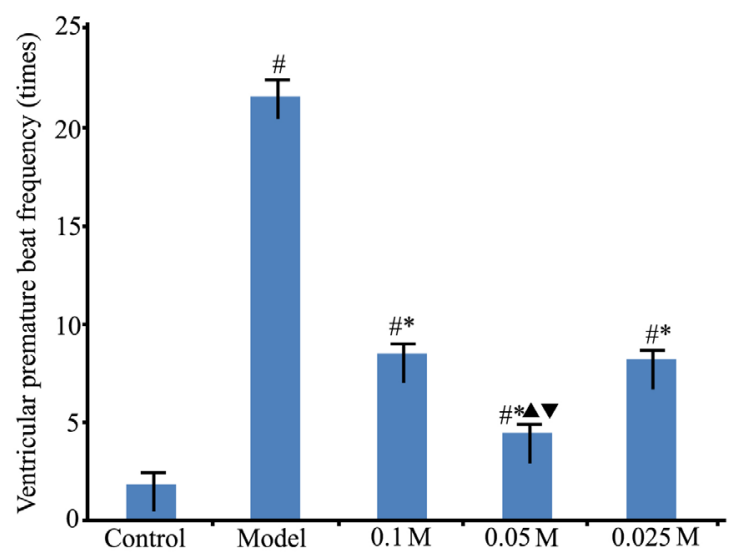

Figure 1. Effect of citrate pretreatment on ventricular premature beat frequency. ${ }^{*} \mathrm{P}<0.05$ compared with the control group. ${ }^{*} \mathrm{P}<0.05$ compared with the model group. ${ }^{\mathrm{p}} \mathrm{P}<0.05$ compared with the $0.1 \mathrm{M}$ citrate group. ${ }^{\mathrm{q}} \mathrm{P}<$ 0.05 compared with the $0.025 \mathrm{M}$ citrate group.

\section{Impact of citrate pretreatment on coupled rhythm and ventricular tachycardia and fibrillation}

Citrate pretreatment markedly reduced the frequency of coupled rhythm and ventricular tachycardia compared to the model group $(\mathrm{P}<0.05)$. In comparison with concentrations of 0.1 and $0.025 \mathrm{M}$, administration of $0.05 \mathrm{M}$ citric acid also significantly diminished their frequency $(\mathrm{P}<0.05$; Figure 2). Ventricular fibrillation (sustained for $10.45 \mathrm{~s}$ ) was observed only one time.

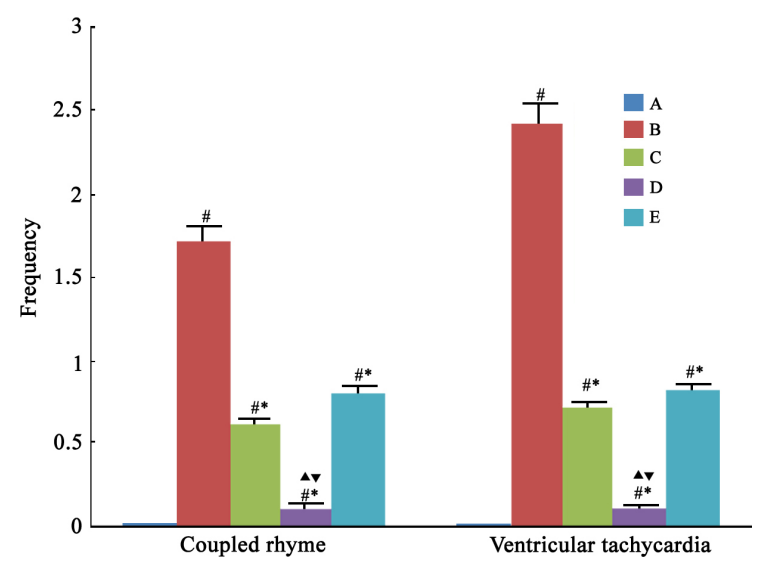

Figure 2. Impact of citrate pretreatment on coupled rhythm and ventricular tachycardia and fibrillation. ${ }^{\#} \mathrm{P}<0.05$ compared with the control group. ${ }^{*} \mathrm{P}<0.05$ compared with the model group. ${ }^{\mathrm{p}} \mathrm{P}<0.05$ compared with the $0.1 \mathrm{M}$ citrate group. ${ }^{\mathrm{P}} \mathrm{P}<0.05$ compared with the $0.025 \mathrm{M}$ citrate group.

Genetics and Molecular Research 15 (4): gmr15048848 


\section{Impact of citrate pretreatment on serum calcium ion concentration}

After treatment with citrate for $5 \mathrm{~min}$, serum calcium ion concentration in groups $\mathrm{C}, \mathrm{D}$, and E fell significantly, by $12.17,16.81$, and $11.25 \%$, respectively $(\mathrm{P}<0.05)$. After 15 min, these concentrations were $8.45,14.11$, and $7.96 \%$ lower than before citrate treatment, respectively, compared to which, they did not obviously differ. Interestingly, after $30 \mathrm{~min}$, serum calcium ion concentration increased, and the level in group D was significantly different from those in groups $\mathrm{C}$ and $\mathrm{E}(\mathrm{P}<0.05)$. Our results demonstrated that the $0.05 \mathrm{M}$ treatment exerted the most striking effect, with maximum chelation occurring after $10 \mathrm{~min}$ (Figure 3).

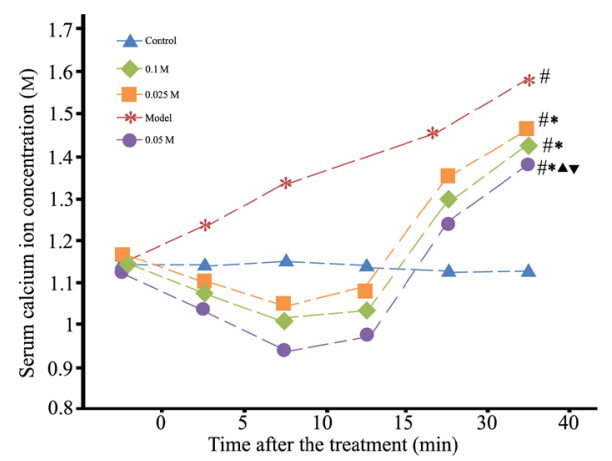

Figure 3. Impact of citrate pretreatment on serum calcium ion concentration. ${ }^{\sharp} \mathrm{P}<0.05$ compared with the control group. ${ }^{*} \mathrm{P}<0.05$ compared with the model group. ${ }^{\mathrm{P} P}<0.05$ compared with the $0.1 \mathrm{M}$ citrate group. ${ }^{\mathrm{q}} \mathrm{P}<0.05$ compared with the $0.025 \mathrm{M}$ citrate group.

\section{Impact of citrate pretreatment on IS/LV, IS/AAR, and AAR/LV}

The IS/LV, IS/AAR, and AAR/LV measurements of rats with I/R injury in the citrate treatment groups were significantly lower compared to those in the model group. In addition, IS/LV and AAR/LV values were markedly lower in the $0.05 \mathrm{M}$ treatment group than in groups $\mathrm{C}$ or $\mathrm{E}(\mathrm{P}<0.05)$, suggesting that this citrate concentration has the strongest impact on IS/LV, IS/AAR, and AAR/LV (Figure 4).

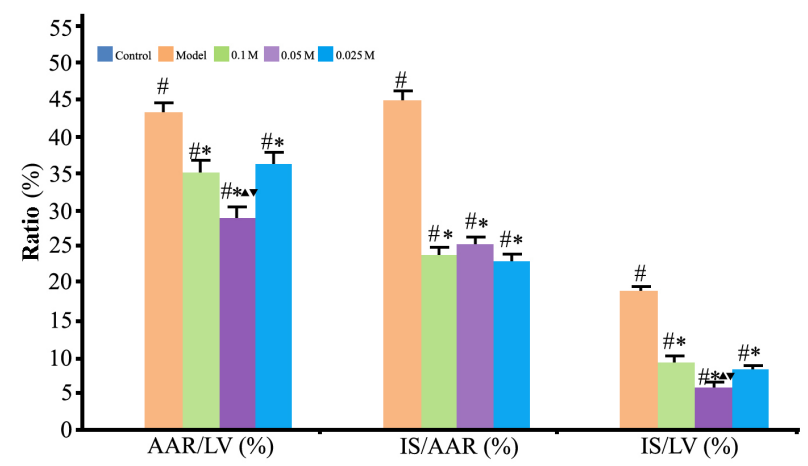

Figure 4. Impact of citrate pretreatment on infarct size (IS) relative to the left ventricle (IS/LV) and area at risk (IS/ $\mathrm{AAR}$ ), and AAR in relation to the $\mathrm{LV}(\mathrm{AAR} / \mathrm{LV})$. ${ }^{*} \mathrm{P}<0.05$ compared with the control group. $* \mathrm{P}<0.05$ compared with the model group. ${ }^{\mathrm{P} P}<0.05$ compared with the $0.1 \mathrm{M}$ citrate group. ${ }^{\mathrm{q}} \mathrm{P}<0.05$ compared with the $0.025 \mathrm{M}$ citrate group. 


\section{Impact of citrate pretreatment on caspase-3 protein expression in myocardial tissue}

As a reference, caspase-3 expression in group A was given a value of 1 , with expression in the other groups being determined relative to this. We found that caspase- 3 protein expression in the citrate-treated groups was down-regulated compared to that in the model group $(\mathrm{P}<0.05)$. As before, $0.05 \mathrm{M}$ treatment resulted in the greatest effect, in this case, in inhibiting caspase-3 expression (Figure 5).

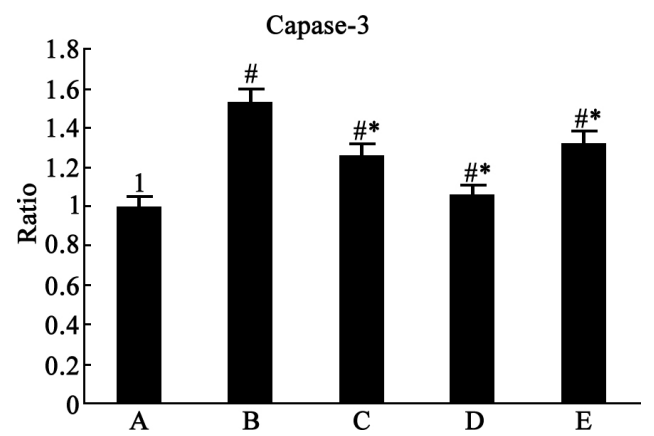

Figure 5. Caspase-3 protein expression in myocardial tissue. ${ }^{\#} \mathrm{P}<0.05$ compared with the control group. ${ }^{*} \mathrm{P}<0.05$ compared with the model group.

\section{Impact of citrate pretreatment on CAM expression in myocardial tissue}

Compared to that in the sham operation group, the expression of CAM in the model group clearly increased, while being markedly reduced in the citrate pretreatment groups (Figure 6). CAM levels were notably suppressed following treatment with $0.05 \mathrm{M}$ citrate, compared to that with 0.1 or $0.025 \mathrm{M}(\mathrm{P}<0.05)$.

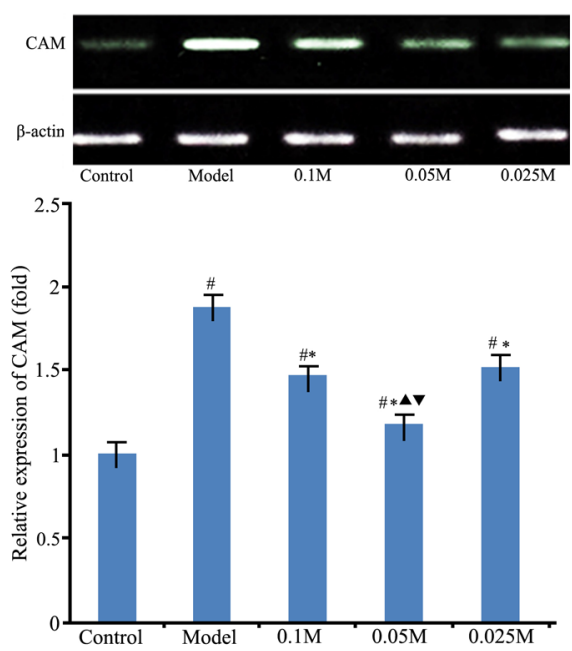

Figure 6. Calmodulin (CAM) expression in myocardial tissue. ${ }^{\#} \mathrm{P}<0.05$ compared with the control group. ${ }^{*} \mathrm{P}<$ 0.05 compared with the model group. ${ }^{\mathrm{p}} \mathrm{P}<0.05$ compared with the $0.1 \mathrm{M}$ citrate group. ${ }^{\mathrm{P}}<0.05$ compared with the $0.025 \mathrm{M}$ citrate group.

Genetics and Molecular Research 15 (4): gmr15048848 


\section{DISCUSSION}

Myocardial I/R injury may lead to malignant arrhythmia. Concerning changes in myocardial cell membrane ion channel structure and function, ventricular electrical remodeling is an important cause of arrhythmia following myocardial infarction (Liu and O'Rourke, 2013; Bell et al., 2015). After myocardial infarction, reentry and "abnormal automaticity" are associated with ventricular arrhythmia. Triggered activity involves delayed and early afterdepolarization, including that induced by action potential extension, and open L-type $\mathrm{Ca}^{2+}$ channels (Wu et al., 2011; Diez et al., 2013; Neckár et al., 2013; Tang et al., 2013). Calcium overload plays an important role in the pathology of myocardial I/R arrhythmia. Ischemia and hypoxia decrease $\mathrm{Na}^{+} / \mathrm{K}^{+}$-ATPase activity, increase $\mathrm{Na}^{+} / \mathrm{H}^{+}$exchange, and heighten intracellular $\mathrm{Na}^{+}$concentration, leading to $\mathrm{Na}^{+} / \mathrm{Ca}^{2+}$ exchange and reduced ATP production. This process also suppresses the uptake of $\mathrm{Ca}^{2+}$ by the sarcoplasmic reticulum and its release from the cell, resulting in cytoplasmic $\mathrm{Ca}^{2+}$ accumulation. Reperfusion supplies high-energy phosphate compounds, and the sarcoplasmic reticulum releases $\mathrm{Ca}^{2+}$. A large quantity of calcium is thus present in the cell, leading to increased amplitude of delayed afterdepolarizations, and ventricular arrhythmia. This study showed that the frequency of ventricular arrhythmia was significantly higher among rats in group $\mathrm{B}$ compared with those in the control group $(\mathrm{P}<$ $0.05)$. Moreover, citrate treatment resulted in lower and higher frequencies than those observed in the model and control groups, respectively, in a dose-independent manner. The 0.05-M group most obviously reduced ventricular arrhythmia, suggesting that citrate can inhibit this pathology in an $\mathrm{I} / \mathrm{R}$ rat model.

$\mathrm{Ca}^{2+}$ is the principal ion responsible for the myocardial cell L-type calcium channel current, which participates in myocardial cell action potential repolarization and the sinoatrial node pacemaker process, activating the sarcoplasmic reticulum to release calcium ions as the main ion flow. It is also involved in myocardial cell excitation-contraction coupling and electrical activity enhancing myocardial contractility (Gonano et al., 2014; Sun et al., 2014). This study revealed that citrate treatment significantly reduced serum calcium ion concentration $(\mathrm{P}<0.05)$, which was lowest $10 \mathrm{~min}$ after administration, before rising again after $30 \mathrm{~min}$, suggesting that citrate has a strong ability to chelate extracellular calcium.

Extracellular calcium ions produce a current via calcium ion channels, and participate in spontaneous depolarization and overshoot in slow- and fast-response cells, respectively. Apoptosis plays a critical role in I/R injury, and is associated with multiple factors, including oxygen free radicals and intracellular calcium overload (Antzelevitch et al., 2011; Kloner et al., 2011). Triggers of apoptosis induce a caspase cascade, with caspase-3 performing a key function. Apoptosis and caspase- 3 overexpression appear in the same region of the ischemic myocardial area (Talukder et al., 2007; Dow et al., 2009). Our results showed that myocardial cell apoptosis increased during the $\mathrm{I} / \mathrm{R}$ process, but caspase-3 protein expression decreased in the citrate-treated groups. Cell apoptosis predominates in early ischemia, whereas necrosis occurs as the degree of ischemia increases. Intracellular calcium overload and abundant free radical production after reperfusion produce irreversible cell apoptosis and aggravate I/R injury. Citrate intervention can protect myocardial tissue through an anti-apoptotic effect. Myocardial infarct size can be reduced to a certain extent, reflecting alleviation of I/R injury. Our data demonstrated that citrate can significantly reduce the area of myocardial infarction and ischemia, further confirming that such pretreatment relieves myocardial damage in rats with $\mathrm{I} / \mathrm{R}$ injury. The mechanism behind this may be related to the chelation of extracellular calcium ions.

Genetics and Molecular Research 15 (4): gmr15048848 
Citrate intervention can reduce intracellular calcium overload caused by influx after myocardial ischemia, and improve myocardial electrical remodeling. Myocardial ischemia and hypoxia inhibit ventricular muscle cell L-type calcium channel current, reduce peak current, and shorten phase two of the cardiac muscle cell action potential. This further accelerates myocardial repolarization, leading to ectopic unified repolarization of ventricular muscle and triggering ventricular arrhythmia. Peak L-type calcium channel current reduction diminishes the effect of calcium on the sarcoplasmic reticulum, triggers intracellular calcium overload to form concussion afterdepolarization, and induces ventricular arrhythmia by triggered activity. On the other hand, intracellular calcium elevation activates the apoptosis signaling pathway. The area of myocardial infarction is related to the degree of myocardial cell apoptosis. Here, the citrate-treated groups showed significantly reduced infarction areas, caspase-3 protein levels, and CAM expression compared to the model group. This indicates that citrate can protect the myocardium by lowering serum calcium ion concentration and caspase- 3 and CAM production, minimizing myocardial cell apoptosis, and relieving ventricular arrhythmia.

The present study investigated the impact of citrate on rats with I/R injury and described the mechanism operating during post-ischemia reperfusion. However, it was limited by the small sample size and lack of an exogenous calcium ion control. Our future research will focus on the role of citrate in the alleviation of myocardial injury, as well as its relationship with calcium ions.

In summary, in a rat model of coronary artery $\mathrm{I} / \mathrm{R}$ via ligation of the left anterior descending coronary artery, our preliminary results highlight the protective role of citric acid against myocardial damage caused by $\mathrm{I} / \mathrm{R}$, which correlated with a reduction in serum calcium ion concentration and decreased expression of caspase-3 and CAM.

\title{
Conflicts of interest
}

The authors declare no conflict of interest.

\section{ACKNOWLEDGMENTS}

\author{
Research supported by the Natural Science Fundation of Hubei Province (\#2014cfa066).
}

\section{REFERENCES}

Antzelevitch C, Burashnikov A, Sicouri S and Belardinelli L (2011). Electrophysiologic basis for the antiarrhythmic actions of ranolazine. Heart Rhythm 8: 1281-1290. http://dx.doi.org/10.1016/j.hrthm.2011.03.045

Barrabés JA, Inserte J, Agulló L, Rodríguez-Sinovas A, et al. (2015). Effects of the selective stretch-activated channel blocker GsMTx4 on stretch-induced changes in refractoriness in isolated rat hearts and on ventricular premature beats and arrhythmias after coronary occlusion in swine. PLoS One 10: e0125753. http://dx.doi.org/10.1371/journal. pone. 0125753

Bell JR, Raaijmakers AJ, Curl CL, Reichelt ME, et al. (2015). Cardiac CaMKII $\delta$ splice variants exhibit target signaling specificity and confer sex-selective arrhythmogenic actions in the ischemic-reperfused heart. Int. J. Cardiol. 181: 288-296. http://dx.doi.org/10.1016/j.ijcard.2014.11.159

Diez ER, Prado NJ, Carrión AM, Petrich ER, et al. (2013). Electrophysiological effects of tamoxifen: mechanism of protection against reperfusion arrhythmias in isolated rat hearts. J. Cardiovasc. Pharmacol. 62: 184-191. http:// dx.doi.org/10.1097/FJC.0b013e318295b611

Dow J, Bhandari A and Kloner RA (2009). The mechanism by which ischemic postconditioning reduces reperfusion arrhythmias in rats remains elusive. J. Cardiovasc. Pharmacol. Ther. 14: 99-103. http://dx.doi. org/10.1177/1074248408329606

Genetics and Molecular Research 15 (4): gmr15048848 
Fanton Y, Robic B, Rummens JL, Daniëls A, et al. (2015). Cardiac atrial appendage stem cells engraft and differentiate into cardiomyocytes in vivo: A new tool for cardiac repair after MI. Int. J. Cardiol. 201: 10-19. http://dx.doi.org/10.1016/j. ijcard.2015.07.066

Gonano LA, Morell M, Burgos JI, Dulce RA, et al. (2014). Hypotonic swelling promotes nitric oxide release in cardiac ventricular myocytes: impact on swelling-induced negative inotropic effect. Cardiovasc. Res. 104: 456-466. http:// dx.doi.org/10.1093/cvr/cvu230

Gonca E and Kurt Ç (2015). Cardioprotective effect of Thymoquinone: A constituent of Nigella sativa L., against myocardial ischemia/reperfusion injury and ventricular arrhythmias in anaesthetized rats. Pak. J. Pharm. Sci. 28: 1267-1273.

Horvat D and Vincelj J (2015). Impact of reperfusion therapy and infarct localization on frequency of premature ventricular beats in acute myocardial infarction. Med. Glas 12: 139-143.

Huang B, Wang X, Yang Y, Zhu J, et al. (2015). Association of admission glycaemia with high grade atrioventricular block in ST-segment elevation myocardial infarction undergoing reperfusion therapy: an observational study. Medicine 94: e1167. http://dx.doi.org/10.1097/MD.0000000000001167

Kloner RA, Dow JS and Bhandari A (2011). The antianginal agent ranolazine is a potent antiarrhythmic agent that reduces ventricular arrhythmias: through a mechanism favoring inhibition of late sodium channel. Cardiovasc. Ther. 29: e36-e41. http://dx.doi.org/10.1111/j.1755-5922.2010.00203.x

Liu T and O'Rourke B (2013). Regulation of the $\mathrm{Na}+\mathrm{Ca} 2+$ exchanger by pyridine nucleotide redox potential in ventricular myocytes. J. Biol. Chem. 288: 31984-31992. http://dx.doi.org/10.1074/jbc.M113.496588

Liu X, Jing G, Bai J and Yuan H (2014). Effect of sufentanil preconditioning on myocardial P-Akt expression in rats during myocardial ischemia-reperfusion. Nan Fang Yi Ke Da Xue Xue Bao 34: 335-340.

Miskolczi G, Gönczi M, Kovács M, Seprényi G, et al. (2015). Further evidence for the role of gap junctions in the delayed antiarrhythmic effect of cardiac pacing. Can. J. Physiol. Pharmacol. 93: 545-553. http://dx.doi.org/10.1139/cipp$\underline{2014-0518}$

Neckár J, Borchert GH, Hlousková P, Mícová P, et al. (2013). Brief daily episode of normoxia inhibits cardioprotection conferred by chronic continuous hypoxia. Role of oxidative stress and BKCa channels. Curr. Pharm. Des. 19: 68806889. http://dx.doi.org/10.2174/138161281939131127115154

Patil KD, Halperin HR and Becker LB (2015). Cardiac arrest: resuscitation and reperfusion. Circ. Res. 116: 2041-2049. http://dx.doi.org/10.1161/CIRCRESAHA.116.304495

Shekarforoush S, Fatahi Z and Safari F (2016). The effects of pentobarbital, ketamine-pentobarbital and ketaminexylazine anesthesia in a rat myocardial ischemic reperfusion injury model. Lab. Anim. 50: 179-184. http://dx.doi. org $/ 10.1177 / 0023677215597136$

Sun X, Zhong J, Wang D, Xu J, et al. (2014). Increasing glutamate promotes ischemia-reperfusion-induced ventricular arrhythmias in rats in vivo. Pharmacology 93: 4-9. http://dx.doi.org/10.1159/000356311

Szepesi J, Acsai K, Sebok Z, Prorok J, et al. (2015). Comparison of the efficiency of $\mathrm{Na}+/ \mathrm{Ca} 2+$ exchanger or $\mathrm{Na}+/$ $\mathrm{H}+$ exchanger inhibition and their combination in reducing coronary reperfusion-induced arrhythmias. J. Physiol. Pharmacol. 66: 215-226.

Talukder MA, Kalyanasundaram A, Zhao X, Zuo L, et al. (2007). Expression of SERCA isoform with faster Ca2+ transport properties improves postischemic cardiac function and $\mathrm{Ca} 2+$ handling and decreases myocardial infarction. Am. $J$. Physiol. Heart Circ. Physiol. 293: H2418-H2428. http://dx.doi.org/10.1152/ajpheart.00663.2007

Tang X, Liu J, Dong W, Li P, et al. (2013). The cardioprotective effects of citric Acid and L-malic Acid on myocardial ischemia/ reperfusion injury. Evid. Based Complement. Alternat. Med. 2013: 820695. http://dx.doi.org/10.1155/2013/820695

Wu YN, Yu H, Zhu XH, Yuan HJ, et al. (2011). Noninvasive delayed limb ischemic preconditioning attenuates myocardial ischemia-reperfusion injury in rats by a mitochondrial K(ATP) channel-dependent mechanism. Physiol. Res. 60: 271-279.

Wu HJ, Yang JY, Jin M, Wang SQ, et al. (2015). Glycyrrhetinic Acid protects the heart from ischemia/reperfusion injury by attenuating the susceptibility and incidence of fatal ventricular arrhythmia during the reperfusion period in the rat hearts. Cell. Physiol. Biochem. 36: 741-752. http://dx.doi.org/10.1159/000430134

Genetics and Molecular Research 15 (4): gmr15048848 